\title{
Bismuth Effect on the Mechanical Properties of Antifriction Al-Sn Alloys
}

\author{
Isai Rosales*, Gonzalo Gonzalez-Rodriguez, Jose Luis Gama, Rene Guardian \\ Centro de Investigación en Ingeniería y Ciencias Aplicadas-FCQ e Ing.UAEM., Cuernavaca, Mexico \\ Email: $\underline{\text { faye12@uaem.mx }}$
}

Received 28 January 2014; revised 3 March 2014; accepted 21 March 2014

Copyright (C) 2014 by authors and Scientific Research Publishing Inc.

This work is licensed under the Creative Commons Attribution International License (CC BY). http://creativecommons.org/licenses/by/4.0/

(c) (i) Open Access

\begin{abstract}
Al-Sn alloys were produced by the induction melting method with different Bi additions. Microstructure shows grains $130 \mu \mathrm{m}$ average size. Fracture toughness and hardness tests have shown that ternary alloying elements present significantly affected the samples with Bi alloying. Plastic deformation was evaluated by using the forging test; the results have shown that the addition of 3.5 at.\% Bi increased the value at least twice as compared with unalloyed sample. Wear test indicated that bismuth slightly affected the tribological behavior. It was found that a concentration of 3.0 at.\% Bi, considerably enhances the alloys performance.
\end{abstract}

\section{Keywords}

EBSD, Mechanical Characterization, Aluminum Alloys, Plasticity, Wear

\section{Introduction}

The applications of Aluminum alloys in aerospace and automotive industry have been the main focus for many years, especially in construction of structural components. However due to the low density of the aluminum alloys, in some structural applications, it is necessary to increase this parameter and also provide the alloy the necessary mechanical resistance to support different loads and bismuth addition may provide this expected performance to the alloys. Among other applications, it is well known that Al-Sn alloys have been investigated for the production of self-lubricant bearing materials [1]. Therefore, friction and wear are of considerable importance in most of the structural components, particularly in bearing applications. Furthermore, strength and microstructure of alloy are also very important factors strongly linked that may affect the wear properties. Other author [2] has investigated the bismuth effect concerning with the oxidation behaviour. So far, no information is available related to the mechanical effect of $\mathrm{Bi}$ in aluminium alloys at these concentrations. For such reason it is

"Corresponding author.

How to cite this paper: Rosales, I., Gonzalez-Rodriguez, G., Gama, J.L. and Guardian, R. (2014) Bismuth Effect on the Mechanical Properties of Antifriction Al-Sn Alloys. Materials Sciences and Applications, 5, 330-337.

http://dx.doi.org/10.4236/msa.2014.55038 
very important to investigate the optimal Bismuth effect addition to Al-Sn alloys and its effect on their mechanical behavior, focussing in the needs of the automotive industry specifically in parts exposed to constant friction and stresses.

\section{Experimental Procedures}

Alloys with nominal concentration of 95 at.\% $\mathrm{Al}$ and $\mathrm{Sn}, \mathrm{Bi}$ additions, were prepared by induction-melting of nominally pure elements in a partial pressure of argon (99.999\% purity). The alloys were drop-cast into copper molds with a diameter of $12.5 \mathrm{~mm}$. Table 1 shows the nominal compositions for the alloys obtained by assuming that weight losses during melting and casting were due to evaporation of $\mathrm{Al}$, therefore, an extra 0.5 at. $\%$ of Al was added to compensate the weight losses. After metallographic polishing, the specimens were etched with Keller's reagent during $5-10 \mathrm{~s}$. The etched specimens were observed in an optical microscope as well in a Leo 450 VP scanning electron microscope equipped with an energy dispersive spectroscopy (EDS) system for determining the Al:Sn:Bi ratios in the alloys. Microhardness tests were evaluated with a Leco 300 AT microhardness tester using a load of $200 \mathrm{~g}$ with a holding time of $15 \mathrm{~s}$. Fracture toughness evaluation was performed based on the ASTM E-399 standard (three point bending procedure). Room temperature plastic deformation vas evaluated in a RCI II vertical Forging machine. Pin-on-disk machine was used to evaluate the wear behavior with a counterpart of AISI-4140 steel (45HRC) at $100 \mathrm{rpm}$ with zero lubrication and a load of $0.2 \mathrm{MPa}$.

\section{Results and Discussion}

\subsection{Microstructure}

The microstructure of samples with different Bi content is shown in Figure 1(a). The sample in the annealing condition shows different zones, where Aluminum majority is present in matrix (dark zones). It can be observed the presence of tin as a separate phase in form of reticular (network) structure, which is obtained by increasing the Sn content (white zones). In Figure 1(b), it is observed the Secondary Electron (SEI) and Electron Back scattering diffraction (EBSD) images, where it can be observed the evolution of the second phase with semicontinuous network distributions of tin on the grain boundaries with bismuth particles segregated preferentially along the white zones. The microstructure of the Al-Sn-Bi alloys depends on the aluminum percentage [3], thus, the bonding between the tin and matrix (Al) was improved at higher tin content ( 3.5 to 4.5 at.\% Bi). It is important to mention that the shape, distribution and the bonding between the tin and aluminum matrix depend highly on the tin percentage.

\subsection{Hardness Measurements}

Figure 2 shows the plots of the microhardness values obtained at room temperature as a function of the bismuth variation. It can be seen that the alloys present a hardness increment when Bi addition it is increased up to 3 at. $\%$ $\mathrm{Bi}$, respect to the alloy without $\mathrm{Bi}$ addition; in this case the alloys with 1.5 and 3.0 at. $\%$ Bi addition shows a similar value, while sample with 4.0 at. $\%$ Bi showed the best response with an increment of approximately $60 \%$.

Table 1. Alloy composition of samples with different element concentration.

\begin{tabular}{cccc}
\hline \multirow{2}{*}{ Alloy Designation } & \multicolumn{3}{c}{ Alloy element content [at.\%] } \\
\cline { 2 - 4 } A1 & Al & Sn & - \\
A2 & 100 & - & - \\
A3 & 95 & 5.0 & 0.5 \\
A4 & 95 & 4.5 & 1.5 \\
A5 & 95 & 3.5 & 3.0 \\
A6 & 95 & 2.0 & 4.0 \\
\hline
\end{tabular}




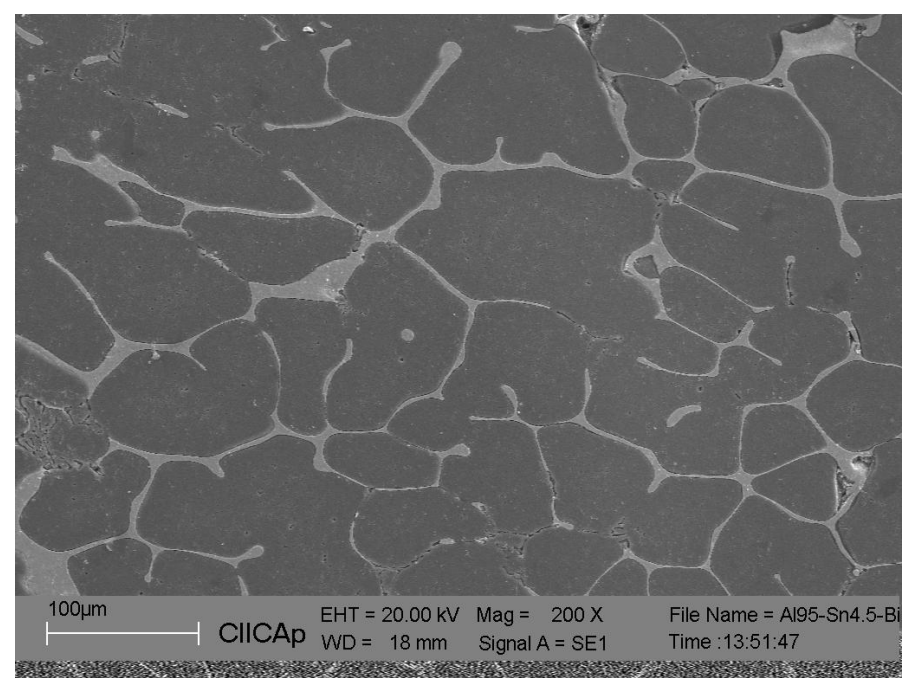

(a)

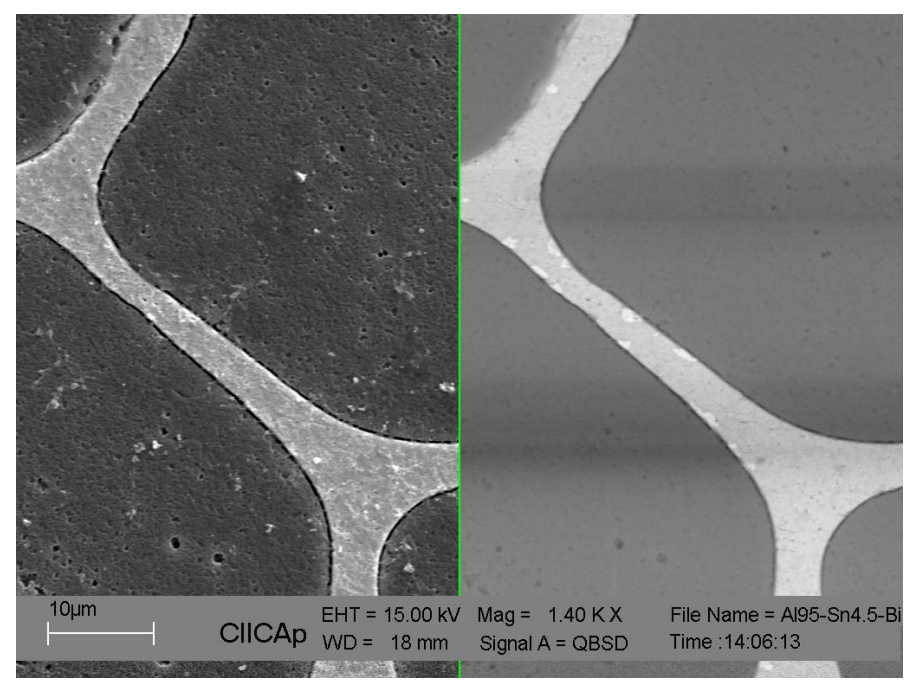

(b)

Figure 1. (a) Microstructure of the surface sample of the alloy with 3.5 at. $\% \mathrm{Bi}$ in annealing condition. (b) Microstructure of the surface sample with 3.5 at.\% Bi, showing the SEI and EBSD mode, where it can be observed the Bi particles in Sn networks.

This increment it is attributed to the precipitation mechanism of a second phase [4] (observed in the microstructure observed in Figure 1(a)). The strengthening due to the refinement of Al matrix and the dispersion of the fine $\mathrm{Sn}$ and $\mathrm{Bi}$ particles in the $\mathrm{Al}$ matrix is considered to be the reason of the increment in hardness of the alloys [5] [6]. Therefore, it is assumed that if Bi particles may produce dislocation movement can be stopped by the above mentioned particles in matrix, therefore, this effect may be the responsible of the improved strengthening.

\subsection{Fracture Toughness}

Figure 3 present the results obtained from the fracture toughness evaluation using the three point bending procedure, where it is clear to observe that the sample with bismuth content lower than 1.5 at.\% Bi present an increment in the toughness value, with exception of sample with 0.5 at. $\%$ Bi which the toughness value has decreased even below the aluminum sample value, in this case perhaps some porosity effect it is assumed. However the alloy that has shown the most significant increment in the toughness value is the sample with 3.0 at. $\%$ Bi with an increment of $50 \%$ compared with the reference sample (aluminum pure). Hahn and Rosenfield 


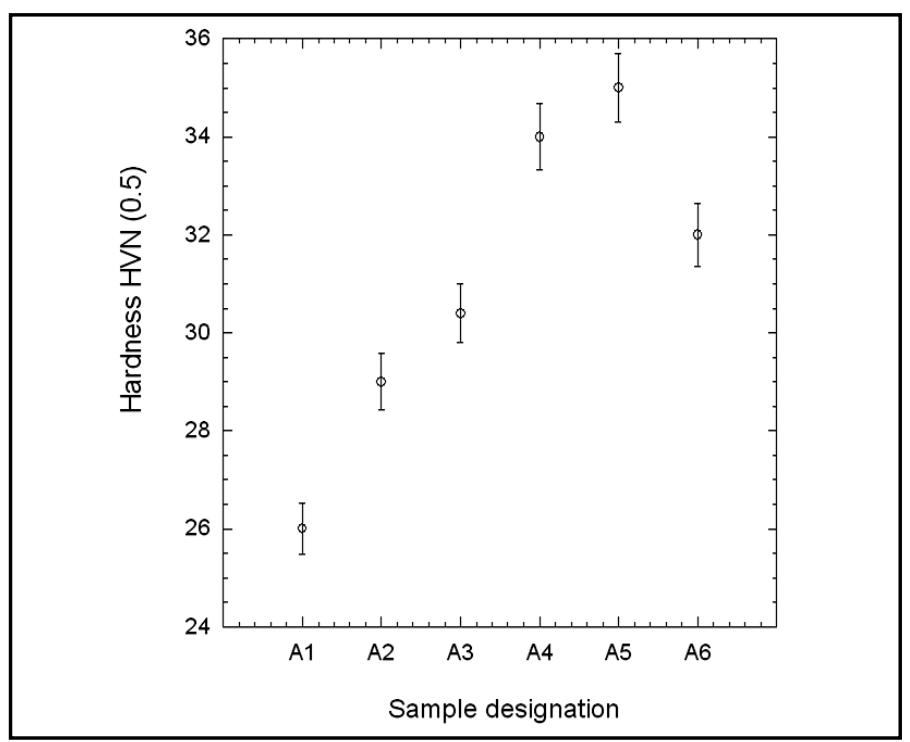

Figure 2. Plot of the hardness tests of the samples with different $\mathrm{Bi}$ content.

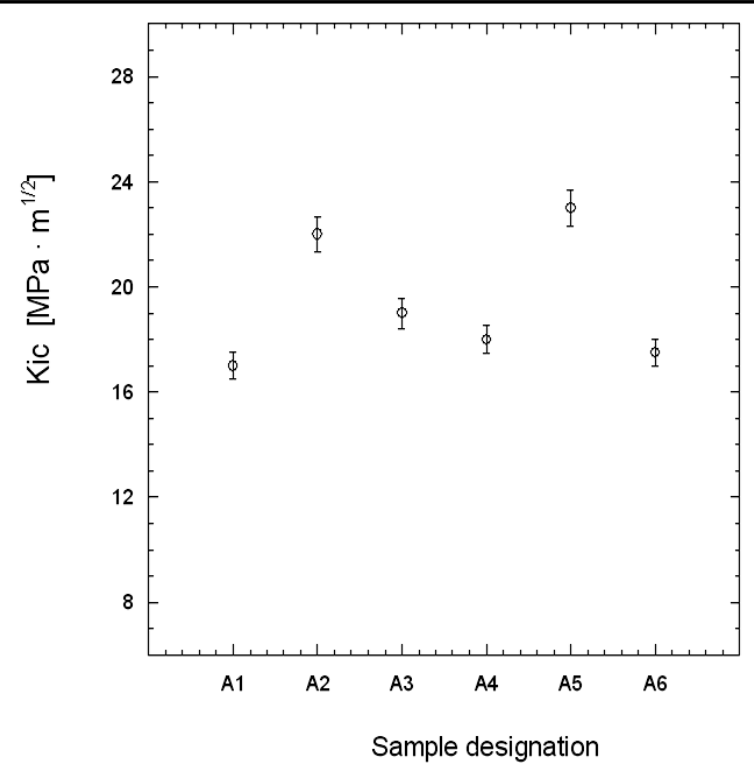

Figure 3. Plot of the Fracture toughness behavior of samples with different $\mathrm{Bi}$ content.

[7] report Factors that affect the fracture toughness of aluminum alloys and precisely this toughening which is attributed to the presence of second phases where Tin and Bi segregation play an important when the flexural strength take place on the bulk sample, stopping the intensity of crack propagation. The importance of the bismuth precipitation inside of the Sn-Al phase, may determine the rate of cracking in samples, being the optimum $\mathrm{Bi}$ value in the order of 3.0 at. $\%$ to be added to reach the best toughening.

\subsection{Deformation Behavior}

Figure 4(a) present the plot obtained from the forging test at room temperature, where it can be seen that the samples with better behavior in comparison with the sample Bi unalloyed and pure aluminum are the samples with 3 and 4 at.\% Bi with a 60 and 55 percent of deformation respectively, which represent approximately twice 
of value of the unalloyed sample.

It is well known that in order to obtain better mechanical properties, it is highly recommendable to produce the cast alloy under a high cooling regime of solidification [4].

In our case, the microstructure was coarse and the grain was wide and quite enlarged after forging test, leading to some positive degree of plasticity at room temperature (Figures 4(b)). Thus, deformation process takes place and the fine bismuth particles interact with the metal matrix while the stress it is being applied, since Bi particles do not operate as obstacle that may stop the deformation processes, that include that particles slides with the matrix material. This statement is supported under the knowledge that small precipitates having suitable distribution and size, enhances the resistance positively affecting toughness [7] [8]. Therefore, if Tin and bismuth segregate to the grain boundaries, an enhanced structure is obtained, providing cohesion between grains. Therefore, we can establish that bismuth addition is in part responsible of the plastic deformation obtained in this alloys.

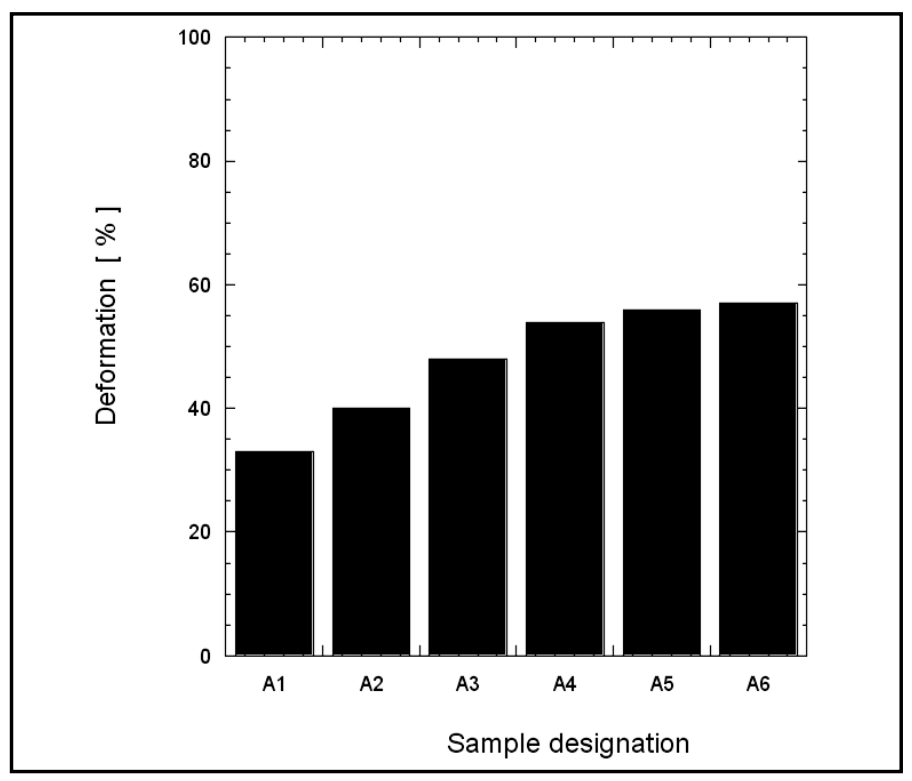

(a)

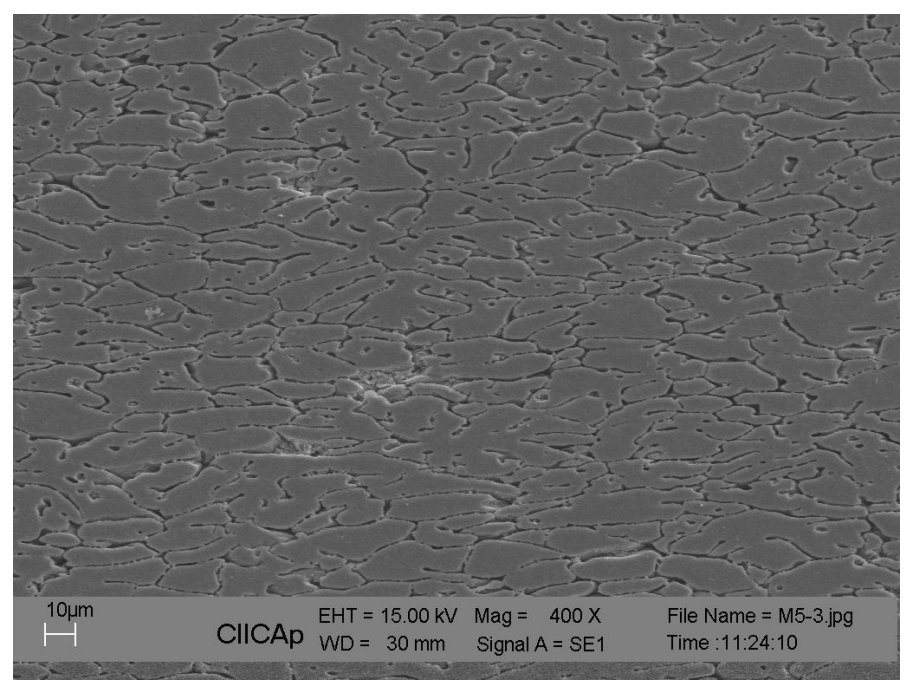

(b)

Figure 4. (a) Plot of the deformation behavior obtained from forging evaluations. (b) Microstructure of the deformed sample (3.5 at.\% Bi) after forging test. 


\subsection{Wear Analysis}

Figure 5(a) and Figure 5(b) show the plot of the weight losses versus sliding distance of worn samples against an AISI 4140 steel under dry sliding conditions and the calculated wear factor obtained from the same curves respectively. Six sets of curves are observed in Figure 5(a) that represents the wear behavior of: pure aluminium, unalloyed sample and samples with different Bi additions with an applied load of 1.0 MPa. In this figure it is very clear that weight losses of the pins increased exponentially over the different samples after one thousand meters, which can be due to that during the initial wear stage process, the generated aluminum oxides remain on the surface sample and after this distance are depleted. Other authors have investigated [9] the effect of nanoscaled particles embedded in aluminum alloys with similar results. On the other hand, the high temperature reached during the wear process, an oxide scale is formed containing the oxidation products of the contact materials produce an abrasive effect. Figure 5(b) shows the obtained values for the wear factor, where it is observed that unalloyed sample present the lowest value of wear factor in comparison with Bi containing samples. Per-

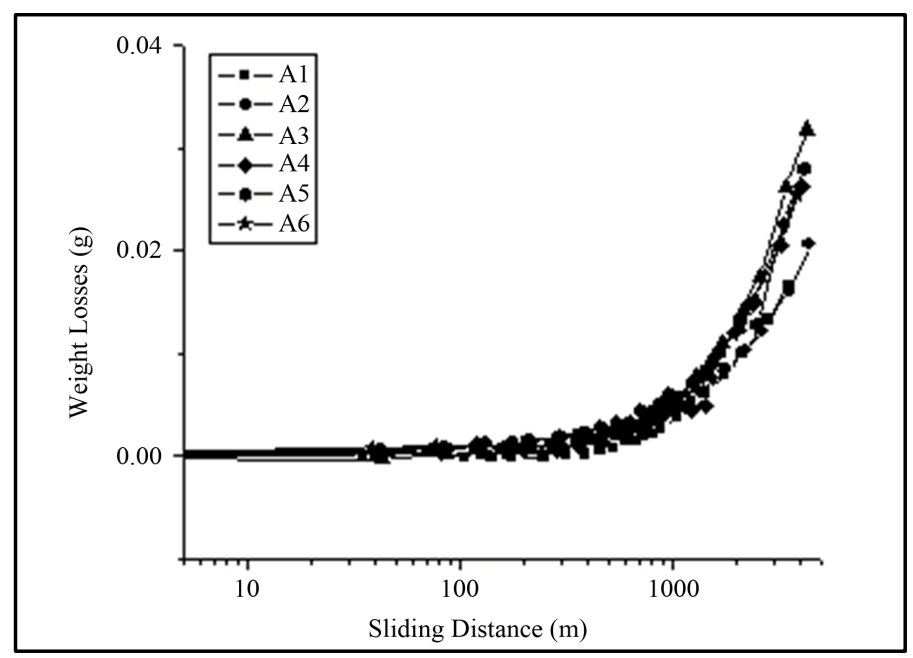

(a)

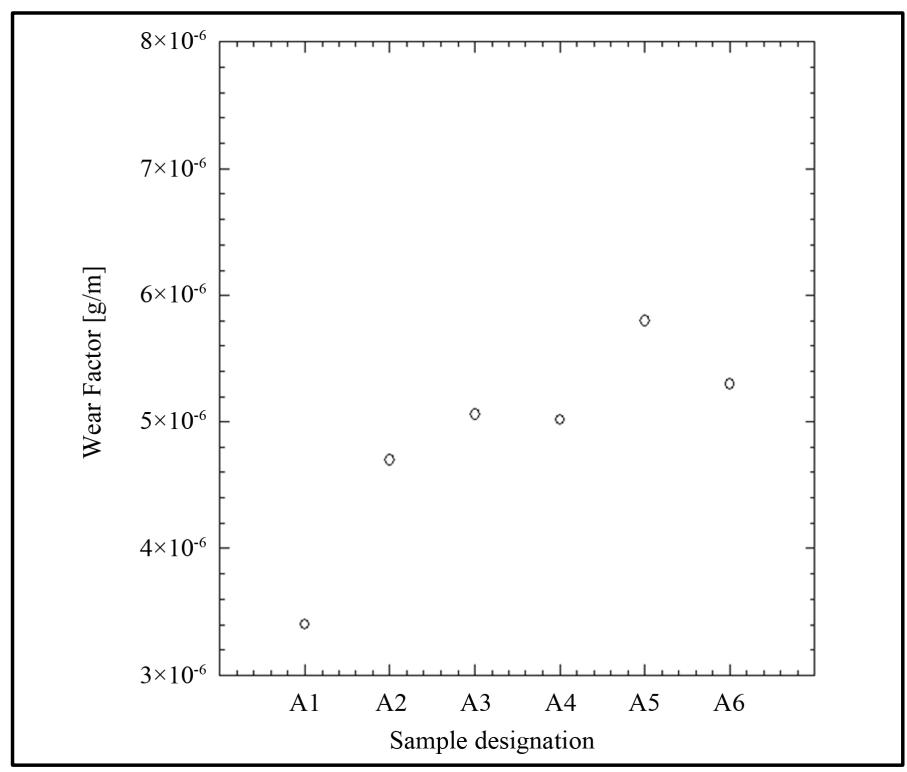

(b)

Figure 5. (a) Plot of the curves of weight losses versus sliding distances from wear tests. (b) Plot of the wear factor obtained from the slopes of the curves of weight losses after wear evaluations. 
haps the strengthening due to the dispersion of the Sn and Bi particles in the Al matrix can be considered in this case to be detrimental in the wear resistance of the alloys, producing an erosive wear mode.

\section{Worn Surfaces Analyses}

The worn surface of the tested alloys are shown in Figure 6(a) and Figure 6(b), where it can be seen that the complete surface area is crossed by grooves generated by the contact of the products deflected from the contact surface of the alloys, also a little amount of particles were observed being depleted out from the wear disk during the evaluation.

Figure 6(a) and Figure 6(b) present the morphology of the surfaces samples corresponding to the alloy with higher and lower bismuth additions respectively. Some layers are observed with regions that present oxide agglomerations, which are characteristics of an intense temperature increment [10]. This phenomenon occur at a short sliding distance, generating a protective lubricant oxide layer, avoiding severe damage to the surface itself, i.e., the generated oxide may provide good layer adhesion which ensures cohesive forces for the contact surfaces. Therefore, in our case, due to an oxide layer formed on the surface sample, this layer remain for some period of

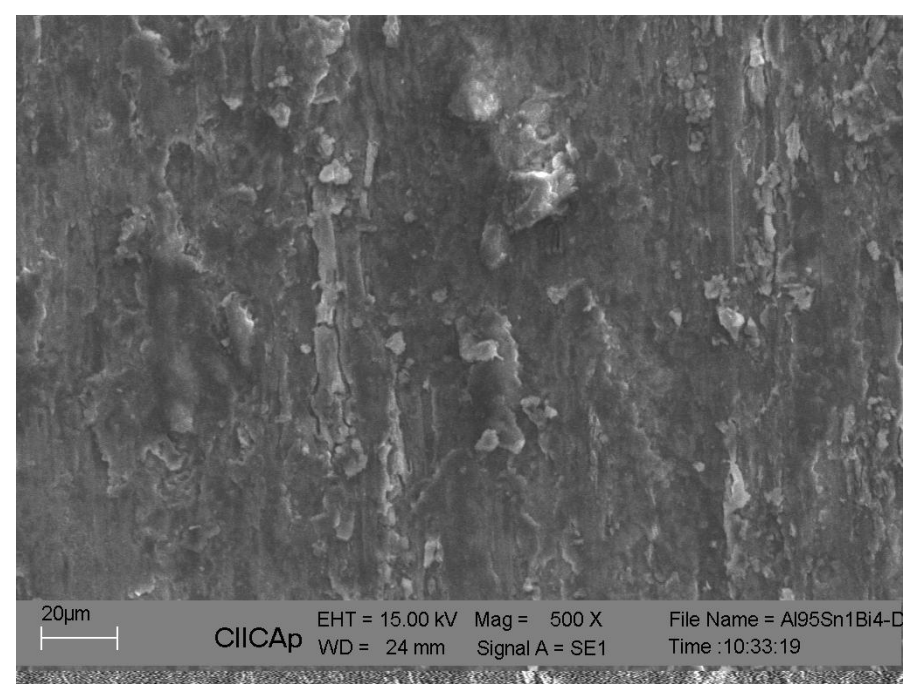

(a)

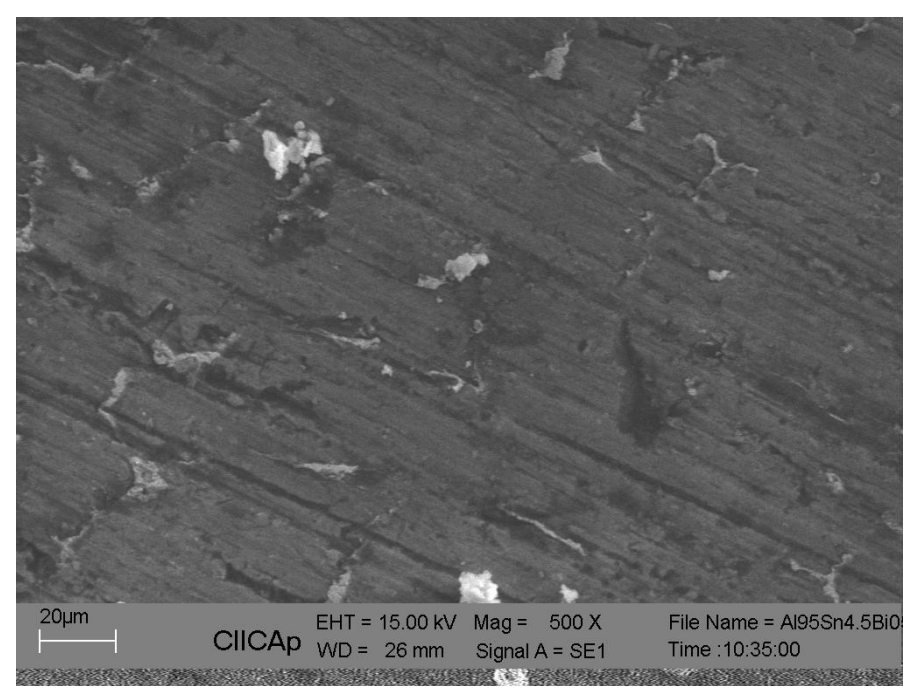

(b)

Figure 6. (a) Worn surfaces images of the sample with high Bi content (4.0 at.\% Bi). (b) Worn surfaces images of the sample with low $\mathrm{Bi}$ content $(0.5$ at. $\% \mathrm{Bi})$. 
time, being flaked out producing weight losses [11]. This can be a cyclic process, producing the oxide layer along the wear process, for longer time of friction exposure protecting the surface sample [12]. As a result of the wear analysis, we conclude that the predominant wear mechanism is adhesive-oxidative type, which is desirable in antifriction materials.

\section{Conclusion}

In this study, we present the interaction of the microstructures of Al-Sn-Bi alloys with the mechanical properties, reporting the optimal Bi concentration to improve the alloys performance. Microstructures have shown a coarse microstructure with Tin segregation trough the grain boundaries, with Bismuth particles inside this second phase. Hardness test studies have shown an increment in approximately $60 \%$, resulting to be directly proportional with the bismuth increment. Moreover, fracture toughness test indicated a noticeable improvement with Bi addition which may provide a better structural response. Deformation test results have shown a considerable increment in the plasticity of the alloys at least twice in comparison with the unalloyed sample. Wear evaluations of the alloys with zero lubrication indicated that the predominant wear mechanism is adhesive type, where Bi additions did not affect negatively the weight losses. Therefore, it is highly recommendable the use of these alloys in parts exposed to a constant friction and a moderate flexural stresses.

\section{Acknowledgements}

Authors want to thank to FCQI-UAEM for permit the use of their facilities in mechanical testing. This work was supported by CONACyT and PROMEP-UAEM PTC-074. Also we would like to thank to W.S. Armes for review this manuscript.

\section{References}

[1] Pathak, J.P. and Mohan, S. (2003) Tribological Behavior of Conventional Al-Sn and Equivalent Al-Pb Alloys under Lubrication. Bulletin of Materials Science, 26, 315-320. http://dx.doi.org/10.1007/BF02707453

[2] Papworth, A. and Fox, P. (1998) The Disruption of Oxide Defects within Aluminium Alloy Castings by the Addition of Bismuth. Materials Letters, 35, 202-206. http://dx.doi.org/10.1016/S0167-577X(97)00244-9

[3] Abed, E.J. (2012) Study of Solidification and Mechanical Properties of Al-Sn Casting Alloys Asian Transactions on Engineering 02 Issue 03, 89-98.

[4] Babu Rao, J., Kamaluddin, S., Appa Rao, J., Sarcar, M.M.M. and Bhargava, N.R.M.R. (2009) Deformation Behavior of Al-4Cu-2Mg Alloy during Cold Upset Forging. Advanced Tribology, 417-421.

[5] Zhao, Y.Q., Wei, J.F., Wu, W.L. and Guo, P. (2007) Research on Semi-Solid Deformation and Forging Behavior of Ti14 Alloy. Materials Science Forum, 546-549, 1373-1378. http://dx.doi.org/10.4028/www.scientific.net/MSF.546-549.1373

[6] Liu, X., Zeng, M.Q., Ma, Y. and Zhu, M. (2008) Wear Behavior of Al-Sn Alloys with Different Distribution of Sn Dispersoids Manipulated by Mechanical Alloying and Sintering. Wear, 265, 1857-1863.

[7] Hahn, G.T. and Rosenfield, A.R. (1975) Metallurgical Factors Affecting Fracture Toughness of Aluminum Alloys. Metallurgical and Materials Transactions A, 653-668.

[8] Kobayashi, T. (2000) Strength and Fracture of Aluminium Alloys. Materials Science Engineering, A286, 333-341. http://dx.doi.org/10.1016/S0921-5093(00)00935-7

[9] Bhattacharya, V. and Chattopadhyay, K. (2004) Microstructure and Wear Behaviour of Aluminium Alloys Containing Embedded Nanoscaled Lead Dispersoids. Acta Materialia, 52, 2293-2304. http://dx.doi.org/10.1016/j.actamat.2004.01.020

[10] Zhu, M. and Gao Y. (2000) Improvement of the Wear Behavior of Al-Pb Alloys by Mechanical Alloying. Wear, 242, 47-53. http://dx.doi.org/10.1016/S0043-1648(00)00397-5

[11] Harris, S.J., McCartney, D.G., Horlock, A.J. and Perrin, C. (2000) Production of Ultrafine Microstructure in Al-Sn, Al-Sn-Cu and Al-Sn-Cu-Si Alloys for Use in Tribological Applications. Materials Science Forum, 331-337, 519-526.

[12] Feyzullahog, E. (2010) The Wear of Aluminium-Based Journal Bearing Materials under Lubrication. Materials and Design, 31, 2532-2539. http://dx.doi.org/10.1016/j.matdes.2009.11.037 